\title{
Signature MicroRNA expression profile is associated with lipid metabolism in African green monkey
}

\author{
Xiao-jun Zhou*, Jin Wang, Hua-hu Ye and Yun-zhi Fa
}

\begin{abstract}
Background: Non-human primates (NHPs) are important models of medical research on obesity and cardiovascular diseases. As two of the most commonly used NHPs, cynomolgus macaque (CM) and African green monkey (AGM) own different capacities in lipid metabolism of which the mechanism is unknown. This study investigated the expression profiles of lipid metabolism-related microRNAs (miRNAs) in CM and AGM and their possible roles in controlling lipid metabolism-related gene expression.

Methods: By small RNA deep sequencing, the plasma miRNA expression patterns of CM and AGM were compared. The lipid metabolism-related miRNAs were validated through quantitative reverse-transcription (RT) polymerase chain reaction (PCR). Related-target genes were predicted by TargetScan and validated in Vero cells.

Results: Compared to CM, 85 miRNAs were upregulated with over 1.5-fold change in AGM of which 12 miRNAs were related to lipid metabolism. miR-122, miR-9, miR-185, miR-182 exhibited the greatest fold changes(fold changes are $51.2,3.8,3.7,3.3$ respectively; all $P<0.01$ ). And 77 miRNAs were downregulated with over 1.5 -fold change in AGM of which 3, miR-370, miR-26, miR-128 (fold changes are 9.3, 1.8, 1.7 respectively; all $P<0.05$ ) were related to lipid metabolism. The lipid metabolism-related gene targets were predicted by TargetScan and confirmed in the Vero cells.

Conclusion: We report for the first time a circulating lipid metabolism-related miRNA profile for CM and AGM, which may add to knowledge of differences between these two non-human primate species and miRNAs' roles in lipid metabolism.
\end{abstract}

Keywords: Lipid metabolism, microRNAs, African green monkey, Cynomolgous macaque

\section{Background}

As short ( $\approx 22-26 \mathrm{nt})$ endogeous RNA molecules that regulate gene expression at the post-transcriptional levels by binding to the 3' untranslated regions (UTRs) of their target mRNAs [1], miRNAs have been described as vital regulators of several biological processes including developmental and metabolic functions. In many pathological conditions such as obesity, type 2 diabetes, cardiovascular diseases, hypertension and cancers, the concentration of miRNA in circulation has been found to be altered [2], suggesting regulatory role in maintaining metabolism homeostasis in humans [3-5].

\footnotetext{
* Correspondence: zhouxiaojun320320@126.com

Laboratory Animal Center, the Academy of Military Medical Sciences, Beijing 100071, People's Republic of China
}

Non-human primates (NHPs) have been vital for medical research due to their close evolutionary relationship, similar behavioral and physiological characteristics to humans. Two of the most commonly used NHPs are Cynomolgus macaque (Macaca fascicularis) and African green monkey (Chlorocebus Sabaeus), which can both be used in studies of neuroscience, infectious diseases and drug safety testing [6-10]. Differences also exist between these two species. For example, AGM has been known to be resistant to simian immunodeficiency virus which can be used as a model organism for HIV research [11, 12]. Also, AGM develops spontaneous hypertension with pathophysiological changes that mimic those of patients with essential hypertension $[13,14]$. Research has also shown that genetic factors influence the atherogenic response of lipoproteins to dietary fat 
and cholesterol in nonhuman primates which reflects different capacities in lipid metabolism between AGM and CM [15].

This study aims to identify the differently expressed miRNAs and their potential targets related to lipid metabolism between AGM and CM. Understanding the roles of miRNAs in lipoprotein and lipid metabolism may eventually lead to development of new disease biomarkers or therapeutic strategies.

\section{Methods}

\section{Animal care and housing}

All protocols were in strict accordance with the recommendations in the Guide for the Care and Use of Laboratory Animals. Animals were housed in troop enclosures with an outdoor facility amd fed nonhuman primate chow per day and a combination of fresh bananas, apples, carrots 3 days per week. As shown in Additional file 1: Table S1, 16 animals were used of which 6 were used for miRNA profiling with the others used miRNA validation.

\section{Plasma collection and lipid level analysis}

All animals were fasted overnight and anesthetized with intramuscular injection (10 to $15 \mathrm{mg} / \mathrm{kg}$ ). Blood samples $(5 \mathrm{ml})$ of CM and AGM were collected from the femoral vein and drawn into EDTA-containing tubes held on ice. Part of the blood samples were separated into plasma and cellular fractions by centrifugation at $1000 \mathrm{~g}$ for $10 \mathrm{~min}$. And the plasma lipid levels were analyzed by an automated chemistry analyzer (Olympus AU5800, Beckman Coulter).

\section{RNA isolation and small RNA deep sequencing}

Total plasma RNA was harvested from the rest blood samples with the TRI Reagent BD (Sigma Aldrich) and the RNeasy mini kit (Qiagen) according to the manufacturers' instructions. In detail, $250 \mu \mathrm{L}$ EDTA-containing plasma was transferred to an Eppendorf tube and mixed thoroughly with TRI reagent, incubated for $5 \mathrm{~min}$ at room temperature, and subsequently mixed with $140 \mu \mathrm{L}$ chloroform. The aqueous phase containing the RNA was carefully removed, and RNA was precipitated by addition of $100 \%$ ethanol. The mixture was applied to an RNeasy Mini spin column and washed several times, and RNA was eluted by addition of $25 \mu \mathrm{L}$ RNase-free water. RNA was stored at $-80^{\circ} \mathrm{C}$ until further processing. Total RNA (4 to $8 \mu \mathrm{g})$ was size fractionated and the small RNAs $(<300 \mathrm{nu}-$ cleotides) were isolated and $3^{\prime}$ extended with a poly(A) tail using poly(A) polymerase. An oligonucleotide tag was then ligated to the poly(A) tail for later fluorescent-dye staining. Hybridization was performed overnight on a microfluidic chip provided by Shanghai KangChen biotechnology company. The hybridization buffer was $6 \times \operatorname{SSPE}(0.9 \mathrm{M} \mathrm{NaCl}$, $60 \mathrm{mM} \mathrm{Na} \mathrm{HPO}_{4}, 6 \mathrm{mM}$ EDTA, pH 6.8) containing 25\% formamide at $34{ }^{\circ} \mathrm{C}$. After RNA hybridization, tag-conjugating $\mathrm{Cy} 3$ and $\mathrm{Cy} 5$ dyes were circulated through the microfludic chip for dye staining. Scanning was performed with the Axon GenePix 4000B microarray scanner. GenePix pro version 6.0 was used to read image raw intensity. The intensity of the the green signal was calculated after background subtraction. The median normalization method was used to acquire normalized data. The threshold value for significance used to define upregulation or downregulation of miRNAs was a fold change $>1.5$, with a value of $P<0.05$ calculated by the $t$ test.

\section{Inhibition of endogenous miRNAs}

Locked nucleic acid (LNA)-modified anti-miRs (Exiqon) were used for the inhibition of endogenous miRNAs in African green monkey-derived Vero cells [16]. Vero cells were maintained in DMEM supplemented with $100 \mathrm{U} / \mathrm{ml}$ penicillin, $100 \mu \mathrm{g} / \mathrm{ml}$ streptomycin, nonessential amino acids, and 10\% fetal bovine serum (FBS) (Invitrogen). Cells were subcultured at $80 \%$ confluency for propagation. Vero cells were subcultured onto 96 well plates and transfected at $>90 \%$ confluency with LNA-modified anti-miRs which were transfected at a final concentration of $10 \mathrm{nM}$ by Lipofectamine 3000 (Invitrogen).

\section{Stem-loop miRNA quantitative RT-PCR}

First, each mature miRNA was extended and reverse transcribed by a sequence specific stem-loop primer using MMLV reverse transcriptase (Takara). Then the reverse transcribed miRNA was quantified by a fluorescently labeled hybridization probe using the strand replacement reaction. and quantitative PCR was performed by an ABI PRISM7500 system (Applied Biosystems). The PCR conditions were as follows: $95^{\circ} \mathrm{C} 3 \mathrm{~min}, 40$ cycles of $95^{\circ} \mathrm{C} 12 \mathrm{~s}$,

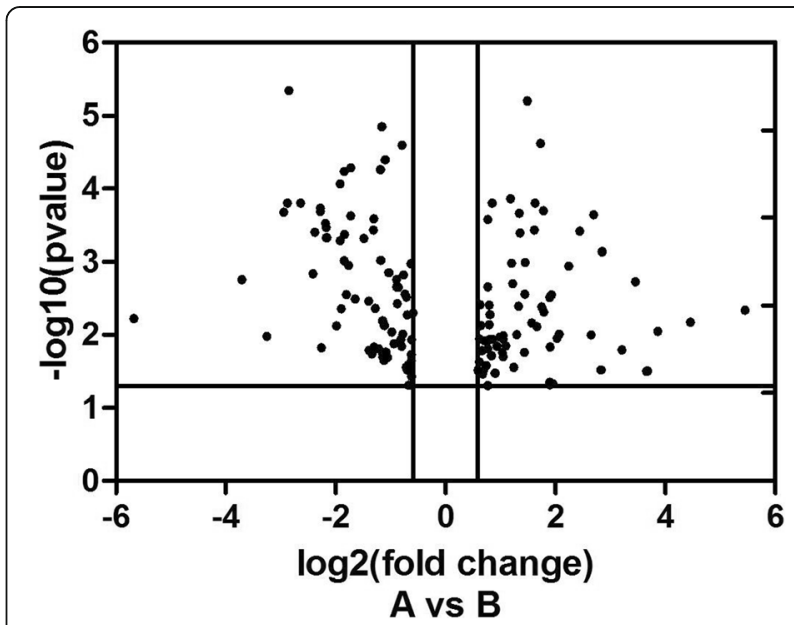

Fig. 1 Volcano plot for the differential expressed miRNA in PBMCs of CM and AGM. A stands for miRNAs upregulated with over 1.5 fold change in CM while B stands for miRNAs upregulated with over 1.5 fold change in AGM $(P<0.05)$ 


\section{Sig GO terms of DE gene-BP}

Single-organism organelie organization [GO:1902589] -

Single-organism localization [GO:1902578] -

Single-organism cellular localization [GO:1902580]-

○.

Count

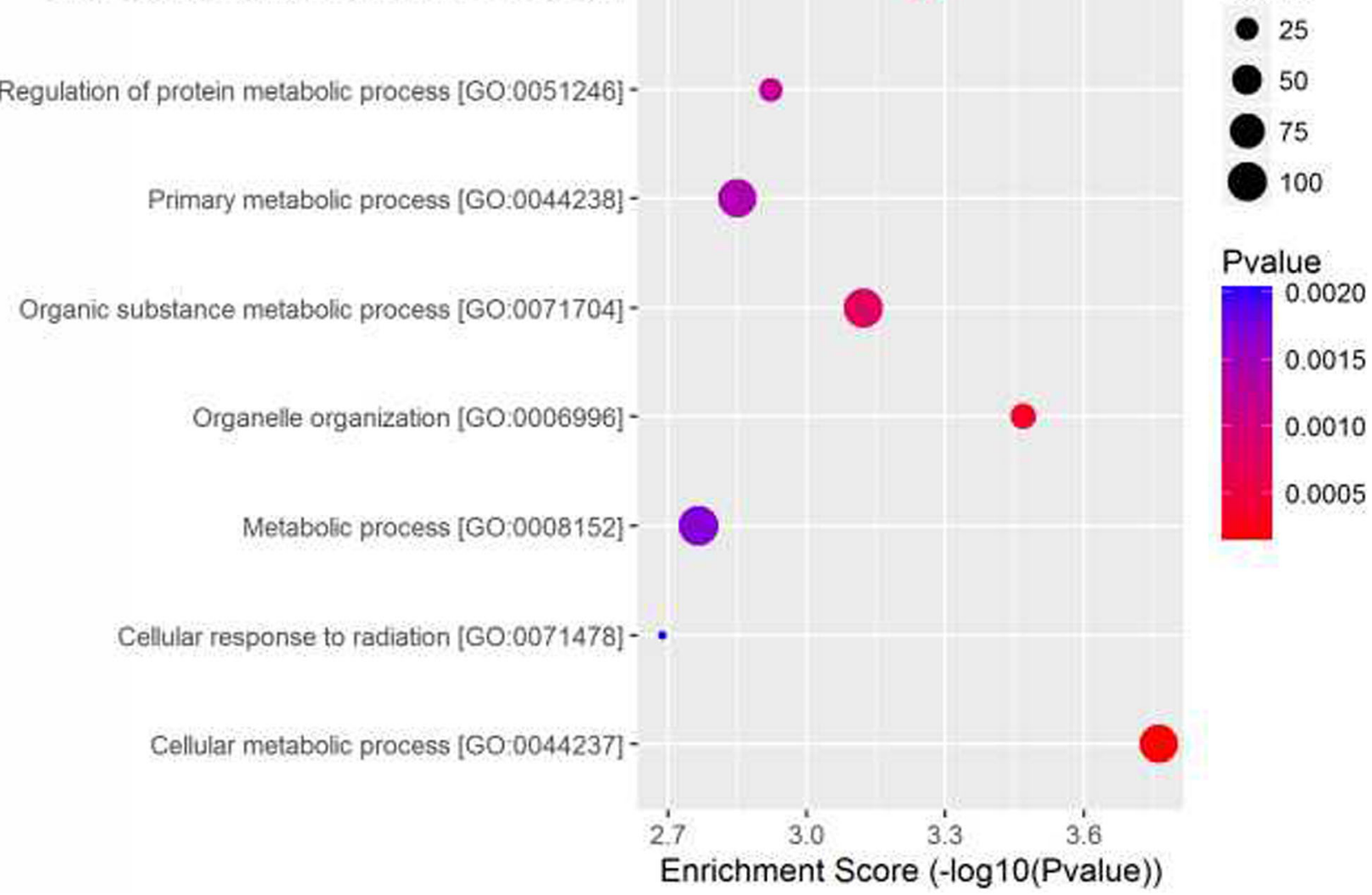

Fig. 2 Enrichment map of $\mathrm{GO}$ categories for biological process. Colors represent $P$ values on a log scale (with red corresponding to the most highly significant, $P<0.05)$. Node size represents the number of genes in a category

Table 1 Properties of lipid metabolism-related miRNAs expressed with over 2 fold change in PBMCs of CM and AGM through small RNA sequencing

\begin{tabular}{lllll}
\hline Upregulated miRNAs & Fold change (AGM/CM) & $P$ & Downregulated miRNAs & Fold change (CM/AGM) \\
\hline hsa-miR-122-5p & 51.2 & 0.006 & hsa-miR-370-3p & 9.3 \\
hsa-miR-9-5p & 3.8 & 0.0005 & & \\
hsa-miR-185-5p & 3.7 & 0.004 & & \\
hsa-miR-182-5p & 3.3 & 0.0002 & \\
hsa-miR-181a-5p & 2.6 & 0.003 & & \\
hsa-miR-144-3p & 2.3 & 0.016 & & \\
hsa-miR-10b-5p & 2.2 & 0.022 & & \\
hsa-miR-148a-3p & 2.2 & 0.02 & & \\
hsa-miR-130b-5p & 2.0 & 0.001 & & \\
\hline
\end{tabular}


$62^{\circ} \mathrm{C} 40 \mathrm{~s}$. miRNAs and related target genes implicated in the regulation of lipid metabolism were obtained through the literature [2]. The RT primers and the primer sets specific for each miRNA amplification designed according the mature miRNA sequence obtained from the miRbase database and shown in Additional file 2: Table S2. Selected miRNAs were further quantified with TaqMan quantitative RT-PCR. mRNA expression levels of the lipid metabolism-related genes predicted to be targeted by miRNAs inhibited by anti-miR transfection were measured by qPCR using SYBR green chemistry [17]. Primer sequences for the target genes are listed in Additional file 3: Table S3.

\section{Western blot analysis}

Anti-miR-treated vero cells were lysed in protein sample buffer containing $50 \mathrm{mM}$ Tris- $\mathrm{HCl}, 150 \mathrm{mM} \mathrm{NaCl} .5 \mathrm{mM}$ EDTA, $0.2 \mathrm{mM}$ sodium orthovanadate, $1 \%$ Triton X-100, $1 \%$ sodium deoxycholate, and $1 \%$ sodium dodecyl sulfate; the buffer was also supplemented with aprotinin $(2 \mu \mathrm{g} / \mathrm{ml})$, pepstatin A $(0.7 \mu \mathrm{g} / \mathrm{ml})$, leupeptin $(0.5 \mu \mathrm{g} / \mathrm{ml})$, and PMSF $(1 \mathrm{mM})$. For each sample, $30 \mu \mathrm{g}$ total protein was electrophoresed through a $10 \%$ sodium dodecyl sulfate-polyacrylamide gel and transfered onto a nitrocellulose membrane.The membrane was blocked by pre-incubation with 5\% skim milk, incubated with the specific rabbit anti-CPT1A (ThermoFisher) and mouse anti-GAPDH (ThermoFisher) overnight at $4{ }^{\circ} \mathrm{C}$, which were detected with horseradish peroxidase-conjugated secondary antibody (Pierce) and visualized with a chemiluminescent substrate (Pierce).

\section{Statistical analysis}

Quantile normalized values for miRNA in each sample were plotted as fold change in comparison with the mean expression of each miRNA within the control group. Significance was assessed by the $t$ test. Statistical analyses were performed using GraphPad Prism version 5.01 .

\section{Results}

\section{Expression profiles of plasma miRNAs in CM and AGM}

As shown in Additional file 1: Table S1, 16 animals were used of which 6 were used for miRNA profiling with the others used miRNA validation. There were no significant differences for weights and plasma lipid levels between the CM and AGM group. We then profiled the plasma miRNA expression in $3 \mathrm{CM}$ and 3 AGM. As shown in Fig. 1, 162 miRNAs exhibited different expression with over 1.5-fold change between CM and AGM. GO analysis for biological process (BP) demonstrated that more genes reside in the categories of metabolic processes (Fig. 2). Among the 85 upregulated miRNAs in AGM, 12 were related to lipid metabolism, while 3 out of 77

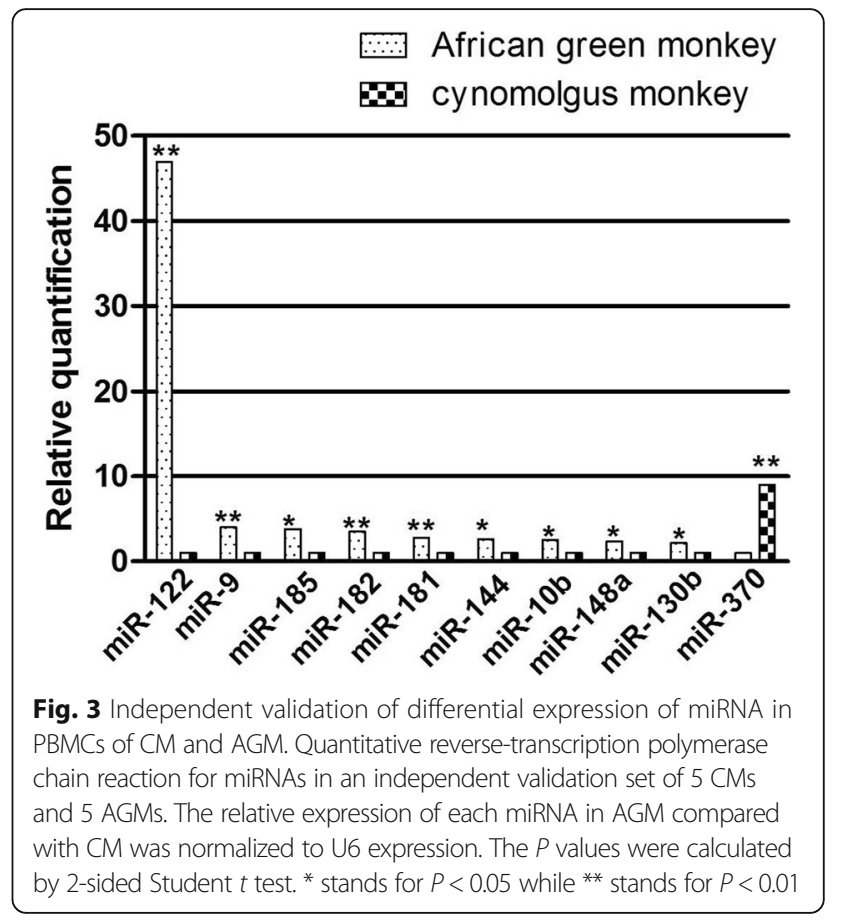

downregulated miRNAs were related to lipid metabolism. miR-122 and miR-370 own the greatest upregulated and donwregulated fold changes $(P<0.05)$, respectively. miRNAs with over 2-fold change related to lipid metabolism are shown in Table 1.

Table 2 Differentially-expressed miRNAs and their predicted targets relevant to lipid metabolism

\begin{tabular}{|c|c|c|c|}
\hline miRNA & $\begin{array}{l}\text { lipid metabolism- } \\
\text { related targets }\end{array}$ & $\begin{array}{l}\text { Number of } \\
\text { binding sites } \\
\text { in AGM }\end{array}$ & $\begin{array}{l}\text { Number of } \\
\text { binding sites } \\
\text { in CM }\end{array}$ \\
\hline hsa-miR-122-5p & AGPAT1 & 2 & 3 \\
\hline hsa-miR-9-5p & ACAT1 & 1 & 1 \\
\hline hsa-miR-185-5p & LDLR & 1 & 1 \\
\hline hsa-miR-182-5p & FBXW7 & 2 & 2 \\
\hline hsa-miR-181a-5p & $\mathrm{IDH} 1$ & 2 & 2 \\
\hline hsa-miR-144-3p & $A B C A 1$ & 6 & 4 \\
\hline \multirow[t]{2}{*}{ hsa-miR-10b-5p } & $\mathrm{ABCA} 1$ & 2 & 1 \\
\hline & $A B C G 1$ & 1 & 1 \\
\hline \multirow[t]{4}{*}{ hsa-miR-148a-3p } & $A B C A 1$ & 1 & 2 \\
\hline & LDLR & 0 & 2 \\
\hline & SIK1 & 2 & 2 \\
\hline & CPT1A & 2 & 1 \\
\hline \multirow[t]{2}{*}{ hsa-miR-130b-5p } & $A B C A 1$ & 6 & 6 \\
\hline & LDLR & 0 & 1 \\
\hline \multirow[t]{2}{*}{ hsa-miR-370-3p } & CPT1A & 2 & 1 \\
\hline & FASN & 10 & 12 \\
\hline
\end{tabular}


Validation of miRNA expression in CM and AGM

To validate the profiling data, miRNAs in Table 1 were further analyzed via quantitative RT-PCR between plasma samples from $5 \mathrm{CM}$ and 5 AGM. Results showed a 48.0-fold increase for hsa-miR-122-5p $(P<0.01)$, a 3.0 4.0-fold increase for hsa-miR-9-5p, hsa-miR-185-5p, hsa-miR-182-5p (all $P<0.05$ ), a 2.0 3.0-fold increase for hsa-miR-181-5p, hsa-miR-144-3p, hsa-miR-10b-5p, hsamiR-148a-3p, hsa-miR-130b-5p (all $P<0.05$ ), and an $\approx 9.5$ decrease for hsa-miR-370-3p $(P<0.01)$ (Fig. 3).

\section{Effects of selected miRNAs on the lipid metabolism- related target genes}

The potential lipid metabolism-related genes targeted by the above miRNAs were selected and analyzed (Table 2). The potential miRNA-target pairs were examined by inhibiting these endogenous miRNAs in Vero cells individually using LNA-modified anti-miRs. Anti-miR treatment may cause the increase on the abundance of mRNA encoded by lipid metabolism-related genes if the predicted target mRNA is indeed suppressed by the endogenous miRNA via mRNA degradation. As shown in Fig. 4, the validated target of hsa-miR-122-5p, hsa-miR-185-5p, hsamiR-181a-5p, hsa-miR-10b-5p, hsa-miR-370-3p was AGPAT1, LDLR, IDH1, ABCG1, CPT1A, respectively. ABCA1 was the target of both hsa-miR-144-3p and hsa-miR-130b-5p. The validated targets of hsa-miR148a-3p included SIK1 and CPT1A. The ABCA1 target mRNA was downregulated after anti-miR treatment, suggesting unconventional effects of hsa-miR-10b-5p. Also, we tested whether the effects of anti-miR treatment on the target genes were similar both at mRNA level and at the protein level. As shown in Fig. 4, anti-miR-370 treatment caused upregulation of CPT1A at the protein level. Further, we tested the effects of every anti-miR treatment on unpredicted targets. As shown in Fig. 4 and Fig. 5, anti-miR-370 treatment caused upregulation of ACAT1 while anti-miR-181a treatment caused upregulation of

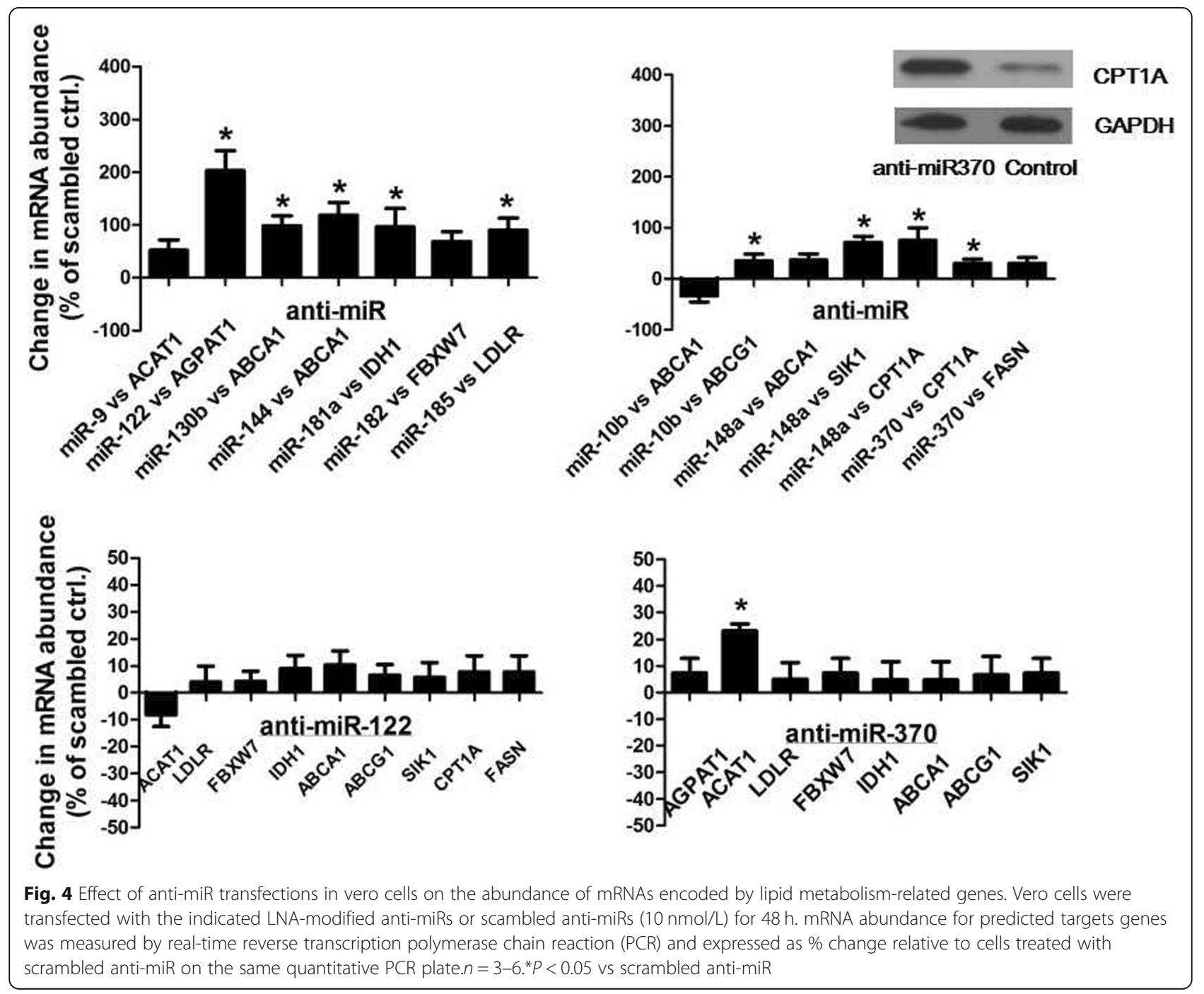




\section{3' UTR targets

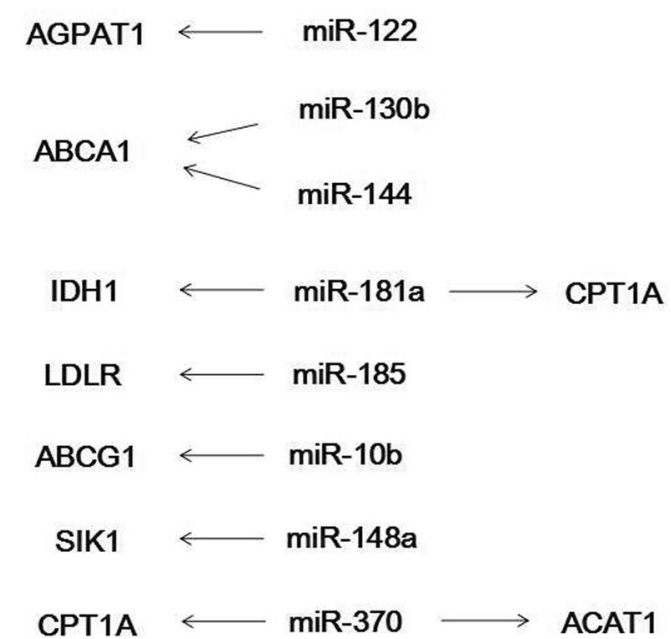

indirect targets

Fig. 5 Schematic show of putative mechanisms through which the up- and down-regulation of specific miRNA can affect lipoprotein metabolism

CPT1A, indicating the indirect targets of miRNA may exist.

\section{Discussion}

As regulators of several physiological processes including developmental and metabolic functions, miRNAs play central role in regulating lipoprotein metabolism and cholesterol homeostasis [18-21]. Many pathological conditions such as familial hypercholesterolemia, cardiovascular diseases, obesity, type 2 diabetes occur when the circulation miRNA concentration alters. miRNAs are stable in plasma and may be suitable as biomarkers in cancers and other diseases [22, 23].

NHPs shares similar characteristics in many aspects to humans when they are used in models of neuroscience, infectious diseases and drug safety testing. And differences also exist between these NHP species like CM and AGM. AGM are resistant to simian immunodeficiency virus and can be used as a model spontaneous hypertension. Besides, genetic differences between CM and AGM influence the diet responsiveness [15]. Although draft genome sequences and transcriptome reconstruction and annotation for CM and AGM have been published [24-26], comparison of miRNA profiling data between these two species lacks.

In this study, we compared the circulating miRNA profile between CM and AGM. Several miRNAs related to lipid metabolism exhibited expression with different levels. miR-122 was significantly upregulated with the greatest fold change in AGM. As the most highly expressed miRNA in the liver, miR-122 has been found to regulate liver lipid metabolism [27-29]. Knockdown of miR-122 in mice decreased expression of genes important for cholesterol biosynthesis, whereas adenoviral overexpression of miR-122 increased cholesterol biosynthesis [30]. miR-122 was found to be downregulated in patients with nonalcoholic fatty liver disease (NAFLD) and knockdown of miR-122 in HepG2 cells recapitulated the lipogenic gene expression profile observes in patients with NAFLD [31]. Thus, we conclude that upregulation of miR-122 renders AGM more capable, compared to $\mathrm{CM}$, in regulating lipoprotein metabolism and cholesterol homeostasis. The validated target of miR-122 in vero cells was AGPAT1 which may cause effect on TG biosynthesis and lipid storage. miR-370 has been shown be significantly downregulated in AGM and target CPT1A which facilitates the transfer of long-chain fatty acids across the mitochondrial membrane for $\beta$-oxidation. Previous research also demonstrate that miR-370 functions in cholesterol biosynthesis by increasing the level of miR-122 [32]. Whether miR-370 exerts an effect on upregulation of miR-122 in AGM still needs investigation.

Other upregulated miRNAs in AGM include miR-185, miR-181a, miR-10b, miR-144, miR-130b,miR-148a with the validated targets of LDLR, IDH1, ABCG1, ABCA1, SIK1 and CPT1A which function in LDL clearance, regulation of lipid biosynthesis and $\beta$-oxidation, HDL biogenesis and cholesterol efflux.

\section{Conclusion}

The present study demonstrates that AGM possess a significantly different miRNA expression profile from CM. The differently expressed miRNAs and their potential targets related to lipid metabolism were investigated, which provide clues that may eventually lead to development of new disease biomarkers or therapeutic strategies.

\section{Additional files}

Additional file 1: Table S1. Sex, age, body weight, and plasma lipid information about CMs and AGMs used. 1 3 and 4 6 are CMs and AGMs used for miRNA profiling, respectively. 7 11 and 12 16 are CMs and AGMs used for miRNA validation, respectively. (DOC $44 \mathrm{~kb}$ )

Additional file 2: Table S2. Sequences of the primers used in the SYBRgreen-based quantitative RT-PCR validation. (DOC $48 \mathrm{~kb}$ )

Additional file 3: Table S3. Primer sequences for miRNA-targeted genes. (DOC $40 \mathrm{~kb}$ )

\section{Abbreviations}

ABCA1: ATP-binding cassette subfamily A member 1; ABCG1: ATP-binding cassette subfamily G member 1; ACAT1: acetyl-CoA acetyltransferase 1; AGPAT1: 1-acylglycerol-3-phosphate O-acyltransferase 1; CPT1A: carnitine Opalmitoyltransferase 1; FASN: fatty acid synthase; FBXW7: F-box and WD-40 domain protein 7; IDH1: isocitrate dehydrogenase 1; LDLR: low-density lipoprotein receptor; SIK1: salt-inducible kinase 1 


\section{Acknowledgments}

We are grateful to Professor Jun-feng Li (Institute of Microbiology and Epidemiology, Beijing, China) for providing the Vero cell line.

\section{Funding}

This study was funded by the National Projects of Infectious Disease under Grant No.2017ZX10304402003.

\section{Availability of data and materials}

Please contact author for data requests.

\section{Authors' contributions}

$X Z$ conceived and designed the experiments. ZY and JW performed experiments. HY helped with the experiments. XZ and YF analyzed the data and wrote the paper. All authors read and approved the final manuscript.

\section{Ethics approval and consent to participate}

Not applicable.

\section{Consent for publication}

Not applicable.

\section{Competing interests}

The authors declare that they have no competing interests.

\section{Publisher's Note}

Springer Nature remains neutral with regard to jurisdictional claims in published maps and institutional affiliations.

\section{Received: 19 April 2018 Accepted: 22 February 2019}

\section{Published online: 28 February 2019}

\section{References}

1. Stark A, Brennecke J, Bushati N, Russell RB, Cohen SM. Animal microRNAs confer robustness to gene expression and have a significant impact on 3'UTR evolution. Cell. 2005;123(6):1133-46. https://doi.org/10.1016/j.cell.2005. 11.023 PMID:16337999.

2. Desgagné $V$, Bouchard L, Guérin R. microRNAs in lipoprotein and lipid metabolism: from biological function to clinical application. Clin Chem Lab Med. 2017;55(5):667-86. https://doi.org/10.1515/cclm-2016-0575 PMID: 27987357.

3. Fernández-Hernando $C$, Ramírez $C M$, Goedeke L, Suárez Y. MicroRNAs in metabolic disease. Arterioscler Thromb Vasc Biol. 2013;33(2):178-85. https://doi.org/10.1161/ATVBAHA.112.300144 PMID: 23325474.

4. Fernández-Hernando C, Suárez Y, Rayner KJ, Moore KJ. MicroRNAs in lipid metabolism. Curr Opin Lipidol. 2011;22(2):86-92. https://doi.org/10.1097/ MOL.0b013e3283428d9d PMID: 21178770.

5. Moore KJ, Rayner KJ, Suárez Y, Fernández-Hernando C. microRNAs and cholesterol metabolism. Trends Endocrinol Metab. 2010;21(12):699-706. https://doi.org/10.1016/j.tem.2010.08.008 PMID: 20880716.

6. Carlsson HE, Schapiro SJ, Farah I, Hau J. Use of primates in research: a global overview. Am J Primatol. 2004;63(4):225-37. https://doi.org/10.1002/ajp. 20054 PMID: 15300710

7. Osada N, Hirata M, Tanuma R, Suzuki Y, Sugano S, Terao K, Kusuda J, Kameoka Y, Hashimoto K, Takahashi I. Collection of Macaca fascicularis cDNAs derived from bone marrow, kidney, liver, pancreas, spleen, and thymus. BMC Res Notes. 2009;2:199. https://doi.org/10.1186/1756-0500-2-199 PMID:19785770

8. Ebeling M, Kung E, See A, Broger C, Steiner G, Berrera M, Heckel T, Inigue L, Alber T, Schmucki R, Biller H, Singer T, Certa U. Genome-based analysis of the nonhuman primate Macaca fascicularis as a model for drug safety assessment. Genome Res. 2011;21(10):1746-56. https://doi.org/10.1101/gr. 123117.111 PMID:21862625.

9. Jones SM, Feldmann H, Stroher U, Geisbert JB, Fernando L, Grolla A, Klenk HD, Sullivan NJ, Volchkov VE, Fritz EA, Daddari KM, Hensley LE, Jahrling PB, Geisbert EW. Live attenuated recombinant vaccine protects nonhuman primates against Ebola and Marburg viruses. Nat Med. 2005;11(7):786-90. https://doi.org/10.1038/nm1258 PMID:15937495.

10. Geisbert TW, Hensley LE, Larsen T, Young HA, Reed DS, Geisbert JB, Scott DP, Kagan E, Jahrling PB, Davis KJ. Pathogenesis of Ebola hemorrhagic fever in cynomolgus macaques: evidence that dendritic cells are early and sustained targets of infection. Am J Pathol. 2003;163(6):2347-70. https://doi. org/10.1016/S0002-9440(10)63591-2 PMID: 14633608

11. Fukasawa M, Miuta T, Hasegawa A, Morikawa S, Tsujimoto H, Miki K, Kitamura T, Hayami M. Sequence of simian immunodeficiency virus from African green monkey, a new member of the HIV/SIV group. Nature. 1988; 333(6172):457-61. https://doi.org/10.1038/333457a0 PMID: 3374586.

12. Apetrei C, Robertson DL, Marx PA. The history of SIVS and AIDS: epidemiology, phylogeny and biology of isolates from naturally SIV infected non-human primates (NHP) in Africa. Front Biosci. 2004;9:225-54 PMID: 14766362.

13. Renna NF, de Las Heras N, Miatello RM. Pathophysiology of vascular remodeling in hypertension. Int J Hypertens. 2013;2013:808353. https://doi. org/10.1155/2013/808353 PMID: 23970958.

14. Rhoads MK, Goleva SB, Beierwaltes WH, Osborn JL. Renal vascular and glomerular pathologies associated spontaneous hypertension in the nonhuman primate Chlorocebus aethiops sabaeus. Am J Physiol Regul Integr Comp Physiol. 2017;313(3):R211-8. https://doi.org/10.1152/ajpregu. 00026.2017 PMID: 28659284

15. Rudel LL. Genetic factors influence the atherogenic response of lipoproteins to dietary fat and cholesterol in nonhuman primates. J Am Coll Nutr. 1997; 16(4):306-12 PMID: 9263179

16. Mladinov D, Liu Y, Mattson DL, Liang M. MicroRNAs contribute to the maintenance of cell-type-specific physiological characteristics:miR-192 targets Na+/K+-ATPase $\beta 1$. Nucleic Acids Res. 2013;41:1273-83. https://doi. org/10.1093/nar/gks1228 PMID: 23221637

17. Kriegel AJ, Fang Y, Liu Y, Tian Z, Mladinov D, Matus IR, Ding X, Greene AS, Liang M. MicroRNA-target pairs in human renal epithelial cells treated with transforming growth factor beta1: a novel role of miR-382. Nucleic Acids Res 2010;38(22):8338-47. https://doi.org/10.1093/nar/gkq718 PMID: 20716515.

18. Rayner KJ, Moore KJ. MicroRNA control of high-density lipoprotein metabolism and function. Circ Res. 2014;114(1):183-92. https://doi.org/10. 1161/CIRCRESAHA.114.300645 PMID: 24385511.

19. Rotllan N, Price N, Patl P, Goedeke L, Fernandez-Hernando C. microRNAs in lipoprotein metabolism and cardiometabolic disorders. Atherosclerosis. 2016;246:352-60. https://doi.org/10.1016/j.atherosclerosis.2016.01.025 PMID: 26828754

20. Goedeke L, Wagschal A, Fernández-Hernando C, Naar AM. miRNA regulation of LDL-cholesterol metabolism. Biochim Biophys Acta 2016;1861(12PtB): 2047:-2052. https://doi.org/10.1016/j.bbalip.2016.03.007 PMID: 26968099.

21. DiMarco DM, Fernandez ML. The regulation of reverse cholesterol transport and cellular cholesterol homeostasis by microRNAs. Biology (Basel). 2015; 4(3):494-511. https://doi.org/10.3390/biology4030494 PMID:26226008.

22. Chin LJ, Slach FJ. A truth serum for cancer:microRNAs have major potential as cancer biomarkers. Cell Res. 2008;18(10):983-4. https://doi.org/10.1038/cr. 2008.290 PMID:18833286

23. Gupta SK, Bang C, Thum T. Circulating microRNAs as biomarkers and potential paracrine mediators of cardiovascular disease. Circ Cardiovasc Genet. 2010;3(5):484-8. https://doi.org/10.1161/CIRCGENETICS.110.958363 PMID·20959591.

24. Chlorocebus aethiops Sabeus (vervet) Sequence Assembly Release. [https://www.ncbi.nlm.nih.gov/assembly/GCF_000409795.2]. Accessed 25 Mar 2014

25. Macaca fascicularis (cynomolgus macaque) Sequence Assembly Release [http://www.ncbi.nlm.nih.gov/assembly/GCF_000364345.1]. Accessed 12 June 2013

26. Lee A, Khiabanian H, Kugelman J, Elliott O, Nagle E, Yu GY, Warren T, Palacio $\mathrm{G}$, Rabadan R. Transcriptome reconstruction and annotation of cynomolgus and African green monkey. BMC Genomics. 2014;15:846. https://doi.org/10. 1186/1471-2164-15-846 PMID:25277458

27. Davis S, Propp S, Freier SM, Jones LE, Serra MJ, Kinberger G, Bhat B, Swayze EE, Bennett CF, Esau C. Potent inhibition of microRNA in vivo without degradation. Nucleic Acids Res. 2009;37(1):70-7. https://doi.org/10.1093/nar/ gkn904 PMID:19015151.

28. Elmen J, Lindow M, Schutz $S$, Lawrence $M$, Petri $A$, Obad S, Lindholm M Hedtjarn M, Hansen HF, Berger U, Gullans S, Kearney P, Sarnow P, Straarup EM, Kauppinen S. LNA-mediated microRNA silencing in non-human primates. Nature. 2008;452(7):896-9. https://doi.org/10.1038/nature06783 PMID:18368051.

29. Esau C, Davis S, Murray SF, Yu XX, Pandey SK, Pear M, Watts L, Booten SL, Graham M, McKay R, Subramaniam A, Propp S, Lollo BA, Freier S, Bennett CF, Bhanot S, Monica BP. miR-122 regulation of lipid metabolism revealed 
by in vivo antisense targeting. Cell Metab. 2006;3(2):87-98. https://doi.org/ 10.1016/j.cmet.2006.01.005 PMID:16459310.

30. Krutzfeldt J, Rajewsky N, Braich R, Rajeev KG, Tuschi T, Manoharan M, Stoffel M. Silencing of microRNAs in vivo with 'antagomirs'. Nature. 2005;438(7068): 685-9. https://doi.org/10.1038/nature04303.

31. Cheuong O, Puri P, Eicken C, Contos MJ, Mirshahi F, Maher JW, Kellum JM, Min H, Luketic VA, Sanval AJ. Nonalcoholic steatohepatitis is associated with altered hepatic MicroRNA expression. Hepatology. 2008;48(6):1810-20. https://doi.org/10.1002/hep.22569 PMID:19030170.

32. Iliopoulos D, Drosatos K, Hiyama Y, Goldberg IJ, Zannis VI. MicroRNA-370 controls the expression the expression of microRNA-122 and Cpt1a and affects lipid metabolism. J Lipid Res. 2010;51(6):1513-23. https://doi.org/10 1194/Jr.M004812 PMID:20124555.

Ready to submit your research? Choose BMC and benefit from:

- fast, convenient online submission

- thorough peer review by experienced researchers in your field

- rapid publication on acceptance

- support for research data, including large and complex data types

- gold Open Access which fosters wider collaboration and increased citations

- maximum visibility for your research: over $100 \mathrm{M}$ website views per year

At BMC, research is always in progress.

Learn more biomedcentral.com/submissions 